\title{
When the grass isn't greener: a case series of young children with accidental marijuana ingestion
}

\author{
Derek Murray, MD*; Joshua Olson, $\mathrm{MD}^{\dagger}$; Ana Sofia Lopez, MSc, MD
}

\section{ABSTRACT}

Marijuana is the most commonly used illicit drug in Canada, with $10 \%$ of the general population admitting to its use in the past year. This high prevalence increases risk of accidental ingestion in young children.

We report four pediatric cases of accidental marijuana ingestion who presented to our local emergency department with altered mental status. Three patients had extensive testing, including one patient who underwent lumbar puncture and empirical treatment for meningitis. To our knowledge, this is the first Canadian case series since $\mathrm{McNabb}$ et al., published over 2 decades ago.

The case series aims to highlight the importance of considering acute marijuana intoxication in the differential diagnosis when assessing young children with altered level of consciousness.

\section{RÉSUMÉ}

La marijuana est la drogue illicite la plus répandue au Canada, et $10 \%$ de la population générale a admis en avoir fait usage au cours de la dernière année. La forte prévalence de la consommation de cette drogue accroitt le risque d'ingestion accidentelle chez les jeunes enfants.

Seront exposés ici quatre cas d'ingestion accidentelle de marijuana chez des enfants amenés au service local des urgences pour une altération de l'état de conscience. Trois d'entre eux ont été soumis à de nombreux examens, dont l'un à une ponction lombaire et à un traitement empirique en raison d'une possible méningite. Il s'agit, à notre connaissance, de la première série de cas semblables au Canada depuis la publication de l'article de $\mathrm{McNabb}$ et de ses collaborateurs il $\mathrm{y}$ a plus de 20 ans.

La série de cas vise à souligner l'importance d'envisager la possibilité d'une intoxication aiguë à la marijuana dans le diagnostic différentiel d'une altération de l'état de conscience chez de jeunes enfants.

Keywords: marijuana, pediatrics, emergency department, ingestion

\section{INTRODUCTION}

Marijuana is the most commonly used illicit drug in Canada, with British Columbia being the highest consuming province. ${ }^{1}$ Acute marijuana intoxication in adults seldom causes significant morbidity. ${ }^{2}$ In contrast, young children can present dramatically, mimicking other serious conditions. We present four cases of accidental marijuana ingestion in children under 5 years of age seen at a community hospital emergency department (ED) over a period of 6 years (2008-2014). Each case had accidental marijuana ingestion as the primary diagnosis on discharge and were seen in consultation by a pediatrician. Urine drug screens were performed using a Beckman Coulter enzyme immunoassay for delta-9-tetrahydrocannabinol and metabolites.

\section{CASE 1}

A previously well 11-month-old girl presented to the ED after an acute onset of diminished tone and poor responsiveness. Vital signs on presentation were heart rate (HR) $110 / \mathrm{min}$, respiratory rate (RR) $24 / \mathrm{min}$, temperature (T) $36.8^{\circ} \mathrm{C}\left(98.2^{\circ} \mathrm{F}\right), \mathrm{SpO}_{2} 97 \%$ on room air, and blood pressure (BP) $95 / 55 \mathrm{~mm} \mathrm{Hg}$. Initial examination demonstrated nuchal rigidity and prompted a thorough meningitis workup, including a complete blood count, electrolyte panel, C-reactive protein, blood cultures, chest $\mathrm{x}$-ray, CT head, urinalysis and lumbar puncture, and an empirical dose of ceftriaxone. The on-call pediatrician could not replicate nuchal rigidity but noted pallor and decreased responsiveness, tone, and reflexes.

The patient's urine drug screen was positive for cannabinoids, whereas the other investigations were normal. The patient's father admitted to smoking marijuana recreationally, and, although he stored it in a locked room, he could not deny the possibility of

From the *Departments of Family Medicine; †Departments of Emergency Medicine, Chilliwack General Hospital, Chilliwack, BC; and $¥ D$ Department of Pediatrics, BC Children's Hospital, Vancouver, BC

Correspondence to: Dr. Derek Murray, Department of Family Medicine, Chilliwack General Hospital, \#508-750 West 12th Avenue, Vancouver, BC, V5Z 0A3; Email: dmurray@qmed.ca 
an accidental ingestion. The patient remained in the ED for observation and was discharged home after the Ministry of Families and Children Development deemed she was safe and offered community follow-up.

\section{CASE 2}

A 3-year-old girl presented to the ED after waking from a nap with excessive sleepiness, lethargy, and poor balance. Past medical history included dextrocardia and subpulmonary valve stenosis, but she had been otherwise completely well prior to this presentation. Vitals were HR120/min, RR 36/min, $\mathrm{T} 36.5^{\circ} \mathrm{C}\left(97.7^{\circ} \mathrm{F}\right)$, BP 98/52 mm Hg. Physical examination was normal, except for tiredness. Response to the examiner was appropriate, and she had no focal neurological deficits.

The consultant pediatrician suspected marijuana ingestion based on resemblance to the previous cases, yet the initial urine toxicology screen was unexpectedly negative. Further investigations included a complete blood count, electrolyte panel, C-reactive protein, vitamin $\mathrm{D}$ and liver function tests-all were normal. The hospital laboratory subsequently reported that the original urine was falsely negative for cannabinoids due to inadequate centrifugation. Both parents reported smoking marijuana recreationally, which was stored on a high shelf in the house. The child was discharged home after she remained in stable condition, with no documentation of Ministry of Families and Children Development involvement.

\section{CASE 3}

A 4-year-old previously well girl reported nausea and became pale while eating dinner. She subsequently lost consciousness for approximately 5 minutes. There was no reported seizure activity, tongue biting, or urinary incontinence. Vitals were as follows: HR 138/min, RR $20 / \mathrm{min}, \mathrm{T} 37.5^{\circ} \mathrm{C}\left(99.5^{\circ} \mathrm{F}\right), \mathrm{SpO}_{2} 99 \%$ on room air, BP $95 / 60 \mathrm{~mm} \mathrm{Hg}$. Physical examination revealed hypotonia and fluctuating level of consciousness, yet she was easily rousable. There were no other neurological abnormalities noted.

Initial workup consisted of a complete blood count, electrolyte panel, urinalysis, and electrocardiogram (ECG). With no clinical improvement, further investigations included a urine toxicology screen, urine culture, and blood cultures. Her urine was positive for cannabinoids, whereas the blood work and ECG were normal.

Her father possessed a medical marijuana licence and reported secure storage of the drug. Moreover, the patient had not recently been at his home. The more likely source were marijuana cookies brought to the mother's home that day by a visitor.

The patient remained in the ED overnight for observation. She was discharged home the following morning, after the fluctuating level of consciousness had resolved. A referral was made to the Ministry of Families and Children Development to provide community follow-up.

\section{CASE 4}

An 8-month- old previously well girl was noted by her parents to have an acute episode of intermittent lethargy and irritability. She was transferred from a neighbouring hospital after cardiac monitoring reportedly demonstrated ventricular tachycardia and premature ventricular contractions. One episode of emesis occurred in transit. On arrival, she was in normal sinus rhythm with a rectal temperature of $37.6^{\circ} \mathrm{C}\left(99.7^{\circ} \mathrm{F}\right)$. On physical examination, she was intermittently lethargic and irritable, with a small, flat anterior fontanel.

Based on the history and similarity to other marijuana ingestion cases, a urinalysis and urine toxicology screen were ordered. The urine was positive for cannabinoids. On further questioning, the patient's mother admitted to smoking marijuana recreationally but denied having any in the household.

The infant was observed in the ED for 6 hours and then discharged with community follow-up from the Ministry of Families and Children Development.

\section{DISCUSSION}

Marijuana consists of components from the hemp plant Cannabis sativa. Marijuana preparations contain over 400 compounds, including delta-9-tetrahydrocannabinol (THC), the main active ingredient with psychoactive properties, and 60 additional cannabinoids. Advances in breeding and cultivation have increased the THC content of recreational marijuana 15 - to 30 -fold in the past 20 years. $^{3}$ 
Marijuana intoxication has been well described in the literature with case reports from different countries, including England, Australia, and Saudi Arabia. ${ }^{4-6}$ Most pediatric data have come from the United States, particularly Colorado, where marijuana became decriminalized in 2009. ${ }^{7}$ Overall, accidental pediatric exposures have increased in U.S. states where marijuana has been decriminalized compared to those where cannabis remains illegal. ${ }^{8}$

There have been no reported deaths in young children from marijuana exposure. Postmortem drug detection records in Ohio (1992-2002) showed that zero of 388 children under 12 years of age tested positive for cannabinoids. ${ }^{9}$ Most cases reported to date in children presented with lethargy and decreased responsiveness ${ }^{4,5,7,10-16}$ and some coma. ${ }^{5,12,15}$ With the increasing potency and availability of marijuana products, ${ }^{3}$ accidental marijuana intoxication in young children will likely become more common.

Marijuana is a Schedule II drug under the Canadian Controlled Drugs and Substances Act, wherein growing, possessing, distributing, and selling cannabis is illegal. Despite this, marijuana is the most commonly used illicit drug in Canada, with British Columbia having the highest use per capita amongst provinces. ${ }^{1}$ Medical marijuana, both possession and production, is legal in Canada with a medical marijuana licence. Only producers licensed by Health Canada may dispense medical marijuana. ${ }^{17}$ As of December 2013, British Columbia accounts for 18,383 of 37,884 personal use licences. ${ }^{18}$ Rising public pressure and changing opinion in Canada could translate to decriminalization in the near future. As demonstrated by Colorado's experience, this could increase pediatric presentations to Canadian hospitals with acute marijuana toxicity.

A 1989 case series at BC Children's Hospital also reported accidental marijuana exposure in children. ${ }^{10}$ Three of the six cases presented in a coma, with one requiring assisted ventilation. Our case series comes from a community hospital with 240 inpatient beds and no pediatric ward serving a local population of 83,000 . Even in such smaller centres, community emergency physicians need to maintain a high index of suspicion for marijuana intoxication when assessing young children presenting with acutely altered level of consciousness.

All of the children seen were previously healthy. Common to all cases, parents noted a sudden and pronounced alteration in consciousness and responsiveness. Vomiting, ataxia, dizziness, agitation, and coma as previously described in case reports were not uniformly present. On physical examination, all four patients had decreased level of consciousness with easy rousability, three were tachycardic, two were hypotonic, and one showed decreased reflexes. None had conjunctival hyperemia documented in the medical record. Except for transient nuchal rigidity in one case, there were no focal neurological deficits. Nuchal rigidity can be an unreliable sign of meningitis in children under 12 months of age. ${ }^{19-21}$

While pattern and symptom recognition obtained through experience can reduce unnecessary investigations, acute marijuana intoxication should remain only one facet of a broad differential diagnosis when assessing young children with altered mentation. Urine drug screens can be misleading, with positive results occurring many days post-exposure, ${ }^{22}$ and do not demonstrate impairment.

In our series, parents reported smoking marijuana recreationally, and one possessed a medical marijuana licence. British Columbia also has the highest number of medical marijuana licences and producers. ${ }^{18}$ It can be postulated that accidental marijuana ingestion (including baked goods) in children will increase, and ongoing safety education for parents should be emphasized.

Study limitations include the possibility that additional cases of accidental marijuana exposure were missed in our search. Confirmatory or quantitative toxicology testing by an alternate method was not performed. Our cases are presumptive that marijuana intoxication was in fact the correct diagnosis.

\section{CONCLUSION}

We report four cases of unintentional marijuana ingestion in children under the age of 5 years presenting as altered mental status to a single community hospital ED. Such presentations are expected to increase in Canada and can lead to extensive investigations and empirical treatment for more serious conditions such as meningitis. A positive urine drug screen for marijuana is helpful but should be considered in the context of excluding more serious pathology. Future work could include public awareness campaigns of the risks of marijuana use in the home.

Competing interests: None declared. 


\section{REFERENCES}

1. Canadian Centre on Substance Abuse. Canadian drug summary. Available at: http://www.ccsa.ca/Resource\%20 Library/CCSA-Canadian-Drug-Summary-Cannabis-2015en.pdf (accessed April 2014).

2. Sidney S, Beck JE, Tekawa IS, et al. Marijuana use and mortality. Am 7 Public Health 1997;87(4):585-90.

3. Asthon CH. Pharmacology and effects of cannabis: a brief review. Br 7 Psychiatry 2001;178:101-6.

4. Robinson K. Beyond reasonable doubt? 7 Clin Forensic Med 2005;12(3):164-6.

5. Boros CA, Parsons DW, Zoanetti GD, et al. Cannabis cookies: a cause of coma. [Abstract] $\mathcal{F}$ Pediatr Child Health 1996;32(2):194-5.

6. Ragab A, Al-Mazroua M, Mahmoud N. Accidental substance abuse poisoning in children: experience of the Dammam Poison Control Center. 7 Clin Toxicol 2014;4:204.

7. Wang GS, Roosevelt G, Heard K. Pediatric marijuana exposures in a medical marijuana state. $7 A M A$ Pediatr 2013;167(7):630-3.

8. Wang GS, Roosevelt G, Le Lait M-C, et al. Association of unintentional pediatric exposures with decriminalization of marijuana in the United States. Ann Emerg Med 2014; 63(6):684-9.

9. Naso C, Jenkins AJ, Younger D. A study of drug detection in a postmortem pediatric population. $\mathcal{F}$ Forensic Sci 2008; 53(2):483-90.

10. Macnab A, Anderson E, Susak L. Ingestion of cannabis: a cause of coma in children. Pediatr Emerg Care 1989;5(4):238-9.

11. Bonkowsky JL, Sarco D, Pomeroy SL. Ataxia and shaking in a 2-year-old girl: acute marijuana intoxication presenting as seizure. Pediatr Emerg Care 2005;21(8):527-8.
12. Carstairs SD, Fujinaka MK, Keeney GE, et al. Prolonged coma in a child due to hashish ingestion with quantitation of THC metabolites in urine. 7 Emerg Med 2011;41(3): 69-71.

13. Pettinger G, Duggan MB, Forrest AR. Black stuff and babies. Accidental ingestion of cannabis resin. Med Sci Law 1988;28(4):310-1.

14. Weinberg D, Lande A, Hilton $\mathrm{N}$, et al. Intoxication from accidental marijuana ingestion. Pediatrics 1983;71(5):848-50.

15. Le Garrec S, Dauger S, Sachs P. Cannabis poisoning in children. Intensive Care Med 2014;40(9):1394-5.

16. Wang GS, Narang SK, Wells K, et al. A case series of marijuana exposures in pediatric patients less than 5 years of age. Child Abuse Neglect 2011;35(7):563-5.

17. Health Canada.Drugs and health products. Available at: http:// www.hc-sc.gc.ca/dhp-mps/marihuana/info/faq-eng.php\#a3 (accessed March 2014).

18. Health Canada. Maribuana Medical Access Program (MMAR) statistics 2013. Available at: http://www.hc-sc.gc.ca/dhp-mps/ marihuana/stat/index-eng.php (accessed June 2014).

19. Levy M, Wong E, Fried D. Diseases that mimic meningitis. Analysis of 650 lumbar punctures. Clin Pediatr 1990; 29(5):254.

20. Walsh-Kelly C, Nelson D, Smith D, et al. Clinical predictors of bacterial versus aseptic meningitis in childhood. Ann Emerg Med 1992;21(8):910-4.

21. Valmari P, Peltola H, Ruuskanen O, Korvenranta H. Childhood bacterial meningitis: initial symptoms and signs related to age, and reasons for consulting a physician. Eur 7 Pediatr 1987;146(5):515-8.

22. Abraham A, Luty J. Testing for illicit drug use in mental health services. Adv Psychiatr Treat 2010;16(5): 369-79. 